\title{
Giant Carbohydrate-rich Cells of the Dinoflagellate Gonyaulax monilata
}

\author{
By LAURA CHUNOSOFF* AND H. I. HIRSHFIELD \\ Biology Department, New York University, Washington Square College of \\ Arts and Science, New York 3, N.Y., U.S.A. \\ (Accepted for publication I August I967)
}

SUMMARY

A small number of organisms in cultures of the dinoflagellate Gonyaulax monilata attained twice the diameter of normal organisms and showed an excessive accumulation of carbohydrate reserves. The nuclei of these giants degenerated as did the cytoplasm. It is suggested that this was not a response to cultural conditions but represented an altered metabolism of individual organisms.

\section{INTRODUCTION}

During a study of the nuclear structure and mitosis in the dinoflagellate Gonyaulax monilata, it was observed that a small percentage of the organisms in actively growing cultures showed an excessive accumulation of carbohydrate reserves and a loss of normal nuclear structure. A comparison between the morphology of normal and carbohydrate-rich forms is presented here.

\section{METHODS}

Cultures of Gonyaulax monilata were supplied by Dr L. Provasoli from the Haskins Collection (Haskins Laboratories, New York City) and were maintained axenically on ST 3 medium (Tatewaki \& Provasoli, 1964) under a I 2 hr light, I2 hr dark cycle. The method of culture, staining procedures, preparation of Epon and paraffin sections were as previously described (Chunosoff \& Hirshfield, 1967).

\section{RESULTS}

The normal Gonyaulax monilata contained a moderate number of large periodic acid-Schiff (PAS)-positive granules situated around the periphery of the organism. Often there was a concentration of these granules between the convex border of the nucleus and the cell wall (P1. I, fig. I). Even when few other PAS-positive granules were present there was usually a crescent-shaped deeply staining area which was flush with the cell wall at the sulcus (Pl. I, fig. I). This is the general area of the origins of the flagella.

The PAS-positive granules were easily thrown to one end of the organism by

* Present address: Department of Biological Sciences, Pace College, 4I Park Row, New York 10038 , N.Y., U.S.A. 
centrifugation at moderate speed for a few minutes. Staining of centrifuged organisms for nucleic acids, carbohydrates and protein (Himes \& Moriber, I956) showed that when the carbohydrate granules were few or moderate in number, the organism was filled with a strongly staining cytoplasm (P1. I, fig. 2).

The normal interphase nucleus had a shallow U-shape. As is the case with other dinoflagellates (Dodge, 1966) the chromatin material within the nucleus was condensed into thick discrete chromosomes. In Gonyaulax monilata these chromosomes run parallel to each other in a tightly packed bundle (Chunosoff \& Hirshfield, 1967). A small proportion of the organisms (estimated to be less than $0.5 \%$ ) in young as well as older cultures attained a diameter of $100 \mu$, twice the normal diameter, and were filled with PAS-positive granules (P1. I, fig. 3). Feulgen-alkaline fast-green-stained preparations of these giant forms showed that the nuclei had lost their normal morphology and appeared as irregularly shaped masses of chromatin. These were usually pushed to one side of the organism by the excessive number of carbohydrate granules (Pl. I, fig. 4). Only a small amount of cytoplasm was present in these forms and was concentrated around the nucleus (Pl. I, fig. 4). In extreme cases the nucleus had completely degenerated and no cytoplasm was detectable. PAS-stained I $\mu$ thick sections of Epon-embedded organisms showed that the granules of both normal and giant forms had colourless centres (Pl. I, figs. 5, 6). Forms with excessive carbohydrate reserves were never observed to divide.

\section{DISCUSSION}

The phenomenon of excessive accumulation of carbohydrate reserves has been observed in several algae when they were grown under heterotrophic conditions and in the presence of glucose (Taylor, 1950; Griffiths, 1965; Rodriguez-Lopez, 1963, 1966). Chlorella grown in a glucose medium increased to two times the normal size and showed a disorganization of chloroplast structure (Rodriguez-Lopez, 1963, 1965). In Gonyaulax monilata accumulation of excessive carbohydrate reserves was accompanied by the degeneration of both nucleus and cytoplasm. However, only a few organisms in a culture exhibited this phenomenon, indicating that 'giantism' is not a general response to the carbohydrate source (glucose) in the medium; it seems more probably to be the result of an altered metabolism of individual organisms.

This work was supported by a research grant (520-A) from the Damon Runyon Memorial Fund.

\section{REFERENCES}

Chunosoff, L. \& HiRshField, H. I. (1967). Nuclear structure and mitosis in the dinoflagellate Gonyaulax monilata. J. Protozool. 14, 157.

Dodge, J. D. (1966). The Dinophyceae. In The Chromosomes of the Algae. Ed. by M. B. E. Godward, p. 96. New York: St Martin's Press.

GRIFFITHS, D. J. (1965). The accumulation of carbohydrate in Chlorella vulgaris under heterotrophic conditions. Ann. Bot. 29, 347.

HIMES, J. \& MORIBER, L. (1956). A triple stain for deoxyribonucleic acid, polysaccharides and proteins. Stain Technol. 31, 67.

RoDrigueZ-LopeZ, M. (1963). Gigantism-inducing factors in Chlorella pyrenoidosa. Nature, Lond. I99, 506. 

Journal of General Microbiology, Vol. 50, No. 2

Plate I
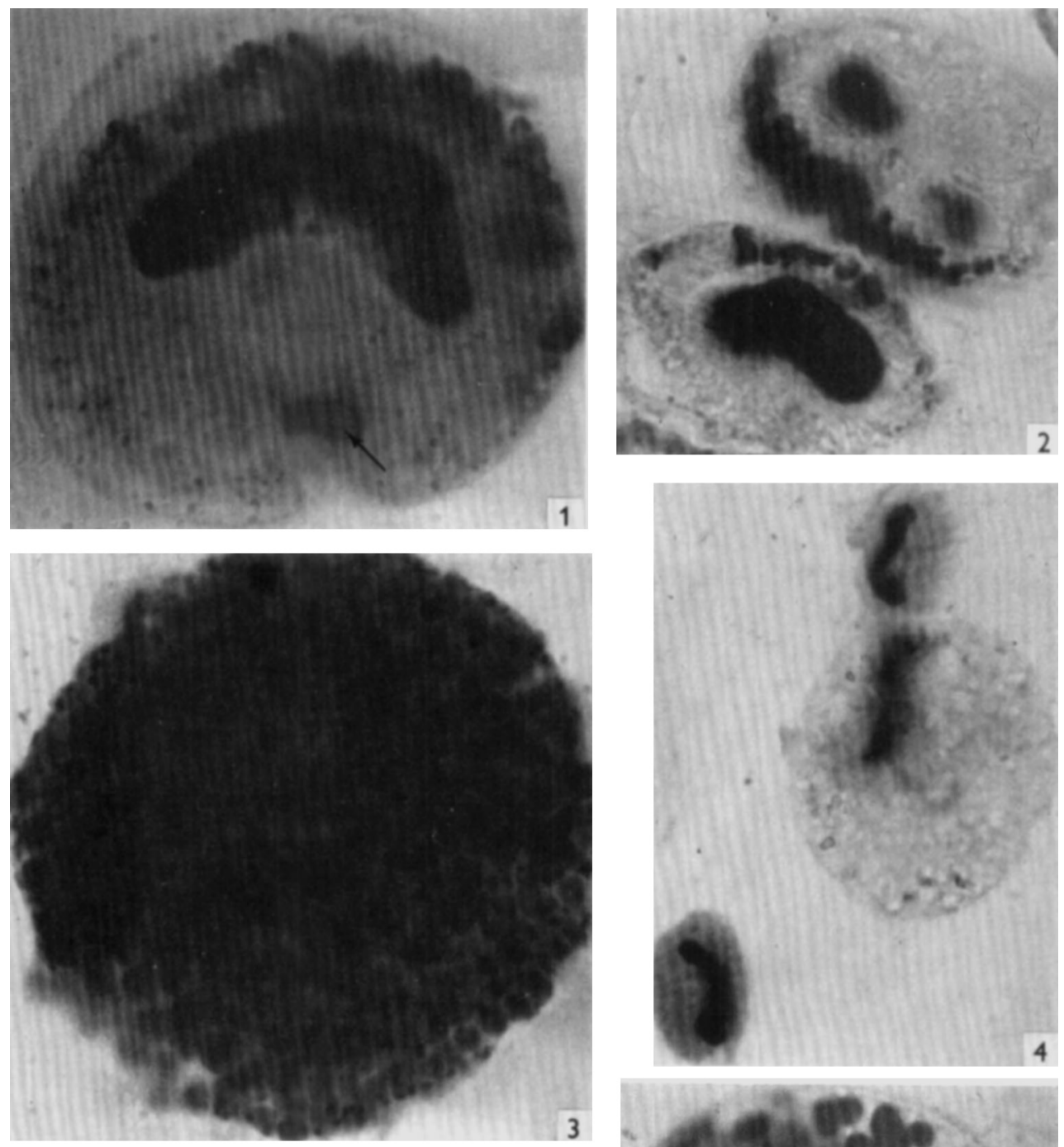

3
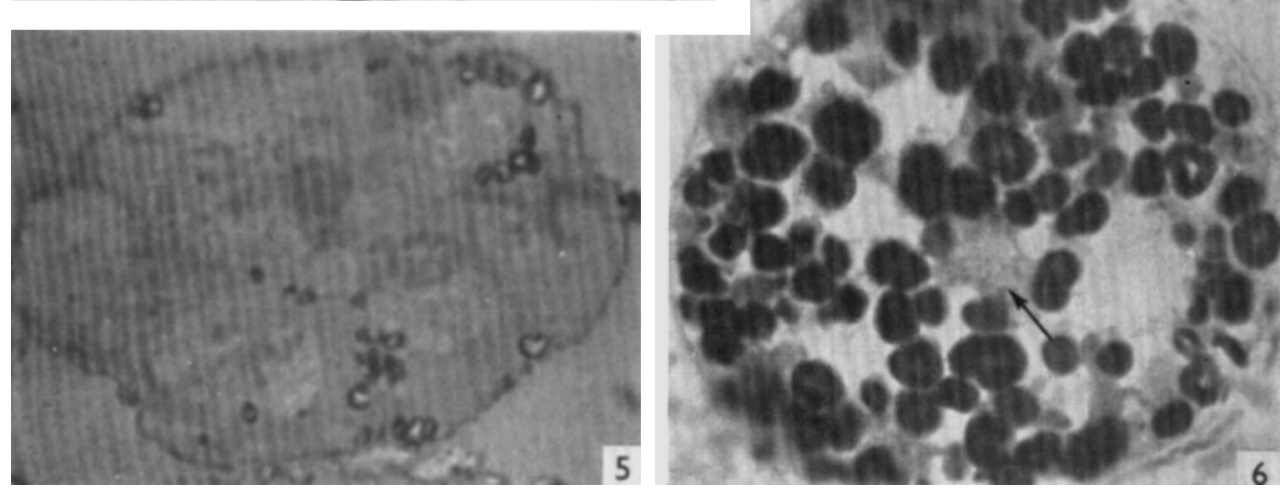

L. CHUNOSOFF AND H. I. HIRSHFIELD

(Facing p. 279) 
RODRIGUEZ-LOPEZ, M. (1965). Morphological and structural changes produced in Chlor ella pyrenoidosa by assimilable sugars. Arch. Mikrobiol. 53, 319.

RODRIGUEZ-LOPEZ, M. (1966). Utilization of sugars by Chlorella under various conditions. J. gen. Microbiol. 43, 139.

Tatewaki, M. \& Provasoli, L. (I964). Vitamin requirements of three species of Antithamnion. Bot. Marina 6, 193.

TAYLOR, F. J. (1950). Oxidative assimilation of glucose by Scenedesmus quadricauda. J. exp. Bot. I, 301 .

\section{EXPLANATION OF PLATE}

Gonyaulax monilata

Fig. I. PAS preparation of normal organism showing carbohydrate granules at periphery and at sulcus (arrow). $\times$ I 300 .

Fig. 2. Organisms in paraffin section stained according to Himes-Moriber technique showing PASpositive bodies, nuclei and cytoplasm. $\times$ I300.

Fig. 3. Giant carbohydrate-rich organism showing numerous PAS-positive granules. Whole mount. $\times 750$.

Fig. 4. Feulgen-alkaline fast-green preparation of giant form (100 $\mu$ diameter). The cytoplasm is concentrated around the nucleus. Normal forms are above and below it. $\times 460$.

Fig. 5. Section (I $\mu$ ) of Epon-embedded normal organism showing cytoplasm and structure of granules. PAS stained. $\times 1300$.

Fig. 6. Section (I $\mu$ ) of Epon-embedded giant form showing structure of granules. PAS stained. A fragment of the nucleus is present (arrow); no cytoplasm visible. $\times 1300$. 
